\title{
Wnt signaling may be activated in a subset of Peutz-Jeghers syndrome polyps closely correlating to LKB1 expression
}

\author{
YAMEI MA ${ }^{1}$, GUOHUA ZHANG ${ }^{2}$, XIANGSHENG FU ${ }^{1}$, OUDONG XIA ${ }^{3}$, CHUNLING ZHAN $^{3}$, \\ LIANJIE LI ${ }^{1}$, ZHIQING WANG ${ }^{1}$ and BAOPING WU ${ }^{1}$ \\ ${ }^{1}$ Department of Gastroenterology, Nanfang Hospital, Southern Medical University, Guangzhou; \\ ${ }^{2}$ Xiaolan Hospital, Southern Medical University, Zhongshan; ${ }^{3}$ Southern Medical University, \\ Guangzhou; ${ }^{4}$ First Hospital of Changsha, Changsha, P.R. China
}

Received November 26, 2009; Accepted February 22, 2010

DOI: $10.3892 /$ or_00000797

\begin{abstract}
The premalignant potential of Peutz-Jeghers syndrome (PJS) hamartomas has not been established. The major gene responsible for PJS is LKB1. LKB1 has a complex cellular role, therefore, the exact role of LKB1 in PeutzJeghers syndrome hamartomas (PJSs) is particularly difficult to understand. It has recently been found that LKB1 functions in the Wnt pathway in Xenopus during early development. Aberrant $\beta$-catenin expression, the key regulator of the activated $\mathrm{Wnt} / \mathrm{B}$-catenin signaling pathway, appears to stimulate interferon-induced gene 1 (IFITM1) products in intestinal tumorigenesis. Both contribute to intestinal tumor formation and tumor progression. This study was designed to investigate expression of LKB1, ß-catenin and IFITM1 in PJSs, colorectal adenomas (CRAs), colorectal carcinomas (CRCs) and normal colorectal mucosas (NCs) using RT-PCR and immunohistochemistry. Immunofluorescence was used to assess the co-expression characteristics of $\beta$-catenin and IFITM1. Results showed that the expression profiles of LKB1, ß-catenin and IFITM1 in PJSs were similar to those in CRAs both at the mRNA and protein levels. The cytoplasmic level of $B$-catenin expression correlated strongly with LKB1 and IFITM1 expression in the tumor cells. The dyregulation of $\beta$-catenin was found in a majority $(16 / 20)$ of the PJS polyps. Immunofluorescence also revealed co-expression of $\beta$-catenin
\end{abstract}

Correspondence to: Dr Baoping Wu, Department of Gastroenterology, Huiqiao Building of Nanfang Hospital, Southern Medical University, Guangzhou, P.R. China

E-mail: baopingwu@gmail.com

Abbreviations: LKB1/STK11, serine/threonine kinase 11; IFITM1, interferon-induced transmembrane protein 1; GSK-3B, glycogen synthase kinase 3B; PJS, Peutz-Jeghers syndrome; RTPCR, Reverse transcription-PCR; IHC, Immunohistochemical; PJSs, PJS hamartoma polyps; NCs, normal colorectal mucosas; CRA, colorectal adenoma ; CRC, colorectal carcinoma

Key words: LKB1, ß-catenin , IFITM1, Peutz-Jeghers syndrome and IFITM1 in the cytoplasm of the PJSs. These findings suggest that Wnt signaling may be activated in a subset of PJSs, and activation of the Wnt/B-catenin signaling in PJS polyps may be caused by LKB1 expression. The activated Bcatenin signaling pathway including IFITM1 might play an important role in a subset of PJS polyps.

\section{Introduction}

Hamartomatous polyps arising in PJS patients are generally considered to lack premalignant potential although rare neoplastic changes in these polyps and an increased gastrointestinal cancer risk in PJS are well documented (1). The constellation of anomalies associated with PJS in humans such as gastrointestinal polyps and epithelial tumorigenesis points to a complex function for LKB1 in various cellular processes $(2,3)$. It has been reported that no correlation exists between the LKB1 mutation and the incidence of cancer $(4,5)$. Yet, several candidate genes are still under investigation which work alone or in concert with the LKB1 gene $(6,7)$. Mechanisms underlying the development of hamartomas and carcinomas are still not fully elucidated (8).

LKB1 has a complex cellular role. It was first identified as a tumor suppressor gene through its association with PJS. To date, the role of LKB1 in cancers is still unknown (9). It has been recently suggested that LKB1 is essential to protect cells from apoptosis under energy stress (10-12). LKB1 is involved in diverse signaling molecules, and studies of the Xenopus LKB1 homolog XEEK (Xenopus early embryonic kinase) support a model in which LKB1 cooperates with the Wnt pathway through its interaction with GSK-3ß (13). Constitutive activation of the Wnt pathway results in the expression of oncogenic genes (14). It is widely accepted that the $\mathrm{Wnt} / \mathrm{B}$-catenin pathway plays an important role in colorectal tumorigenesis $(15,16)$. Aberrant $\beta$-catenin expression, the key regulator of the activated $\mathrm{Wnt} / \mathrm{B}$-catenin signaling pathway, might stimulate interferon-induced gene 1 (IFITM1) products. Up-regulation of IFITM1 appears to be an early event in $\beta$-catenin intestinal tumorigenesis. IFITM1 may serve as a downstream regulator of $\beta$-catenin in $\mathrm{Wnt}$ signaling $(17,18)$. IFITM1 is specifically induced in colorectal tumors and modulates the invasiveness of gastric 
cancer cells (19). The pathogenesis of PJS may involve dysregulation of the Wnt signaling pathway (20). Nevertheless, the expression of IFITM1 in cancer is poorly understood, and the regulatory mechanisms behind B-catenin accumulation in PJS are still unclear. Previous studies have found that up to $85 \%$ of all sporadic colorectal cancers have mutations in APC (14), which is the main cause of B-catenin activation in colorectal cancers. In contrast to the majority of colorectal tumors, PJS is not caused by mutations in the APC gene $(21,22)$. Since PJS is an inherited disease with an increased risk for gastrointestinal cancers (23), whether B-catenin and IFITM1 play a similarly important role in the development of PJS polyps warrants further investigated. To date, research regarding the activation of $\beta$-catenin and IFITM1 in PJS is lacking. Moreover, there are no available data on the relevant expression of LKB1 and B-catenin signaling molecules in human colorectal tumors at different stages of progression.

In this study, we examined the expression profiles of LKB1, B-catenin and IFITM1 in PJSs, and compared the findings to normal colorectal mucosas (NCs), CRAs and CRCs, to determine whether Wnt signaling plays a role in the pathogenesis of PJS and to identify its potential regulatory mechanisms in PJS.

\section{Materials and methods}

Patients and tissue samples. This research was carried out in accordance with the ethical guidelines of the Research Review Committee of our institution. Freshly frozen specimens and formalin-fixed paraffin-embedded tissues were available from 20 PJS patients from Nanfang Hospital, and these polyps were diagnosed histopathologically as hamartomatous polyps. Hematoxylin and eosin (H\&E) staining was performed to determine the histology. The histologic aspects of the PJS polyps were unambiguous in all cases. Fig. 1 shows the typical histological characteristics of the PJS tumors.

The diagnostic criteria for PJS include the presence of characteristic mucocutaneous pigmentaion, the presence of small bowel hamartomatous polyps and a family history of PJS. Patients needed to fulfill two of these three criteria for a clinical diagnosis of PJS to be made (24).

We also investigated a total of 50 colorectal tumors including 25 adenocarcinomas and 25 adenomas. In addition, the macroscopically and microscopically uninvolved areas of regular colonic mucosa in endoscopic resected segments of the colorectum from PJS patients were included in the investigations. The following factors were determined for all patients: age, gender, tumor size, tumor location (left location, right location or rectum) of PJSs and other colorectal tumors.

$R N A$ isolation and semiquantitative RT-PCR. Total RNA was extracted from the frozen tissues using TRIzol reagent (Takala, Japan) according to the manufacturer's instructions for performing RT-PCR. The RNA concentration was quantitated by measuring the absorbance at $260 \mathrm{~nm}$ and was reversely transcripted to cDNA. RT-PCR was performed with $0.2 \mu \mathrm{g}$ of RNA in a 32-cycle reaction (20 $\mu \mathrm{l}$ total volume; Fermentas, Lithuania) according to the manufacturer's recommendations. The cDNA samples were then subjected to PCR analysis using the following primers: GAPDH, forward 5'-CCATGGAGAAGGCTGGGG-3' and reverse 5'CAAAGTTGTCATGGATGACC-3' (197-bp product); LKB1, forward 5'-CTGCTGAAAGGGATGCTTG-3' and reverse 5'-CACCGTGAAGTCCTGAGTGTAG-3' (252-bp product); ß-catenin, forward 5'-ACAAACTGTTTTGAAAA TCCA-3' and reverse 5'-CGAGTCATTGCATACTGTCC-3'; IFITM1, forward 5'-GGTGCTGTCTGGGCTTCAT-3' and reverse 5'-AGGCTATGGGCGGCTACT-3' (249-bp product). Cycle conditions of the PCR were as follows: initial denaturation $\left(5 \mathrm{~min}\right.$ at $95^{\circ} \mathrm{C}$ ) followed by 32 cycles of amplification consisting of denaturation ( $30 \mathrm{sec}$ at $94^{\circ} \mathrm{C}$ ), annealing for $40 \mathrm{sec}$ $\left(\mathrm{GAPDH}, 58^{\circ} \mathrm{C}, \mathrm{LKB} 1, \beta\right.$-catenin and IFITM1, $\left.58^{\circ} \mathrm{C}\right)$ and elongation $\left(45 \mathrm{sec}\right.$ at $\left.72^{\circ} \mathrm{C}\right)$, and annealing $\left(10 \mathrm{~min}\right.$ at $\left.72^{\circ} \mathrm{C}\right)$. Products were separated by electrophoresis on a $2 \%$ agarose gel. The results were expressed as the ratio of the relative levels.

Immunohistochemistry and evaluation. The specimens were routinely fixed in formalin and subsequently embedded in paraffin. Before staining, 2- $\mu \mathrm{m}$ paraffin-embedded tissue sections were mounted on Superfrost Plus slides, deparaffinized with xylene and graded alcohol and then rehydrated with distilled water. Endogenous peroxidase activity was blocked by placing the slides in 3\% hydrogen peroxidase/methanol for 10 min followed by a rinse with tap water. Antigen retrieval entailed placing the slides in a pressure cooker with an antigen unmasking solution $(0.01 \mathrm{M}$ citrate buffer, $\mathrm{pH}$ 6.0) for $1 \mathrm{~min}$. Slides were subsequently incubated with the primary antibodies $\left(4^{\circ} \mathrm{C}\right.$ overnight): rabbit polyclonal anti-IFITM1 (Boster, Wuhan, China), mouse monoclonal ß-catenin and polyclonal LKB1 (Santa Cruz Biotechnology, Santa Cruz, CA, USA), which were used at a dilution of 1:400. The slides were then incubated with secondary biotinylated anti-rabbit and anti-mouse IgG, and streptavidin-biotin peroxidase 3'3' diaminobenzidine (DAB) was used as chromogen. Finally, sections were counterstained with hematoxylin. The negative control included an empty control with normal secondary biotinylated IgG instead of the primary antibodies. Breast cancer tissue was used as a positive control.

Assessment of the expression of LKB1 and IFITM1 was based on the previous studies, respectively $(25,26)$. Immunoreactivity for $\beta$-catenin was estimated quantitatively with reference to previous repots (27), and the staining of the membrane, cytoplasm and nucleus was assessed separately. Staining scores were calculated by semiquantitative optical analysis, using the multiplied product of the percentage of positive cells from 0 to 100 and the staining intensity from 1 to 3 (1, weak; 2, moderate; and 3, strong), which was then divided by 3 , allowing for a range in scores from 0 to 100 .

Double-labeled indirect immunofluorescence staining. The slides were routinely deparaffinized with xylene and graded alcohol, permeabilized with $1 \%$ Triton in phosphate-buffered saline for $10 \mathrm{~min}$, and incubated with $10 \%$ normal goat serum blocking solution (Bostor, Wuhan, China) for $1 \mathrm{~h}$. Doublelabeled indirect immunofluorescence was performed with polyclonal anti-IFITM1 and monoclonal anti- $\beta$-catenin 


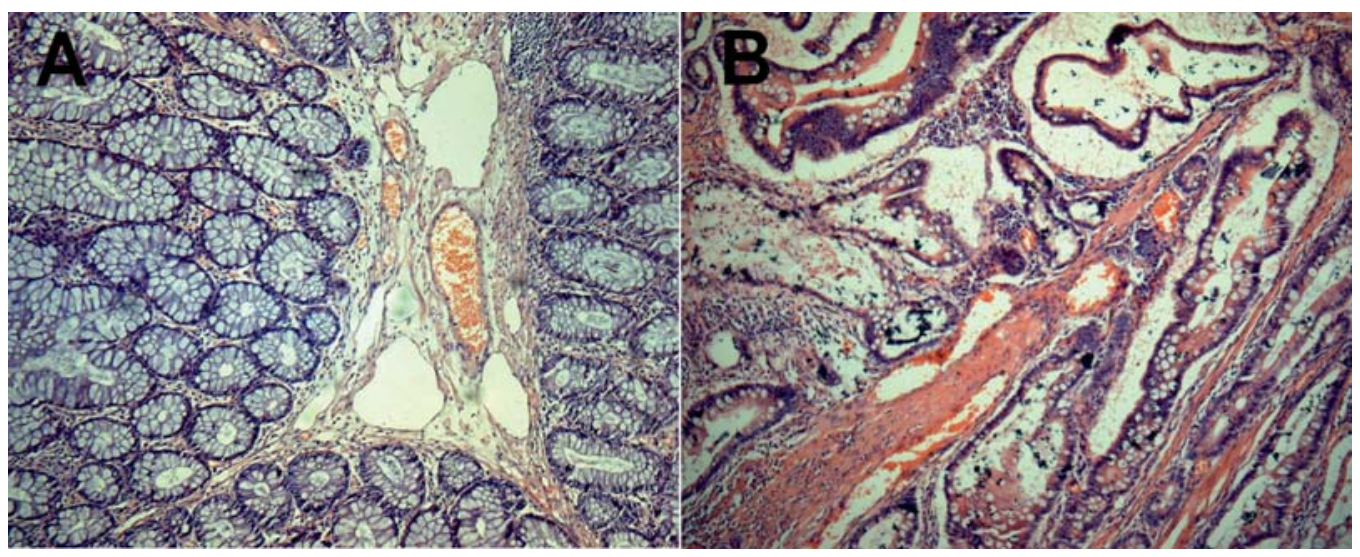

Figure 1. A typical Peutz-Jeghers syndrome polyp demonstrating elongated, frond-like epithelium with cystic dilation of glands overlying an arborizing network of smooth muscle bundles by H\&E staining (A) and PJS carcinomas comprised primarily of epithelial cells (B) are shown.

Table I. Clinicopathologic characteristics of the patients.

\begin{tabular}{|c|c|c|c|c|}
\hline & PJSs $(n=20)$ & CRAs $(n=25)$ & CRCs $(n=25)$ & $\operatorname{NCs}(n=20)$ \\
\hline \multicolumn{5}{|l|}{ Gender } \\
\hline Male/Female & $11 / 9$ & $18 / 7$ & $14 / 11$ & $11 / 9$ \\
\hline $\begin{array}{l}\text { Age (years) } \\
\text { (range) }\end{array}$ & $\begin{array}{c}25.0 \pm 9.5^{\mathrm{a}} \\
(13-47)\end{array}$ & $\begin{array}{c}45.8 \pm 17.9^{a} \\
(13-74)\end{array}$ & $\begin{array}{c}56.1 \pm 9.8^{b} \\
(40-82)\end{array}$ & $\begin{array}{c}25.0 \pm 9.5 \\
(13-47)\end{array}$ \\
\hline \multicolumn{5}{|l|}{ Location } \\
\hline Right location & $9(45 \%)$ & $15(60 \%)$ & $10(40 \%)$ & $9(45 \%)$ \\
\hline Left location & $10(50 \%)$ & $5(20 \%)$ & $9(36 \%)$ & $10(50 \%)$ \\
\hline Rectum & $1(5 \%)$ & $5(20 \%)$ & $6(24 \%)$ & $1(5 \%)$ \\
\hline $\begin{array}{l}\text { Average size }(\mathrm{mm}) \\
\text { (range) }\end{array}$ & $\begin{array}{c}17.25 \pm 10.24 \\
(4-40)\end{array}$ & $\begin{array}{c}18.08 \pm 10.54 \\
(6-50)\end{array}$ & $\begin{array}{l}28.72 \pm 11.50^{c} \\
\quad(13-60)\end{array}$ & NA \\
\hline \multicolumn{5}{|l|}{ Dysplasia } \\
\hline Mild & 2 & 7 & NA & NA \\
\hline Moderate to severe & 0 & 18 & & \\
\hline \multicolumn{5}{|c|}{ Histology of the dysplasia } \\
\hline Well & NA & NA & 5 & NA \\
\hline Moderately to poor & & & 20 & \\
\hline
\end{tabular}

Right location includes the cecum, ascending colon and transverse colon; Left location includes the descending colon and sigmoid colon.

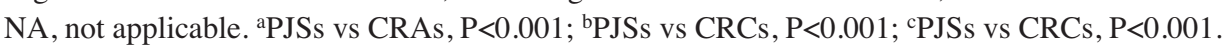

(dilution 1:100), which were detected with fluoresceinconjugated anti-rabbit and rhodamine-conjugated anti-mouse secondary antibodies (both from Jackson, USA). The nuclei were visualized with DAPI (Sigma, $0.5 \mathrm{~g} / \mathrm{ml}$ ), and the immunostainings were viewed and documented with a Zeiss Axiophot microscope.

Statistical analysis. Differences in mRNA expession were evaluated with one-way ANOVA. The $\chi^{2}$ test was used to assess the reduced membranous expression. A one-way ANOVA and LSD were used to assess the differences in staining intensity. Spearman correlation coefficients were used to determine whether there was a positive or negative correlation. Differences were considered significant at values of $\mathrm{P}<0.05$. Analyses were carried out using SPSS version 13.0 (SPSS, Chicago, IL, USA).

\section{Results}

Clinical characteristics of the Peutz-Jeghers syndrome patients. PJS polyps occur throughout the alimentary tract. In the present study we analyzed PJS polyps located in the colorectum. The clinicopathological features of the PJSs and the colorectal tumors are summarized in Table I. No significant differences were found for gender and location of the polyps among the PJSs, CRAs and CRCs $(\mathrm{P}>0.05)$. The 
A

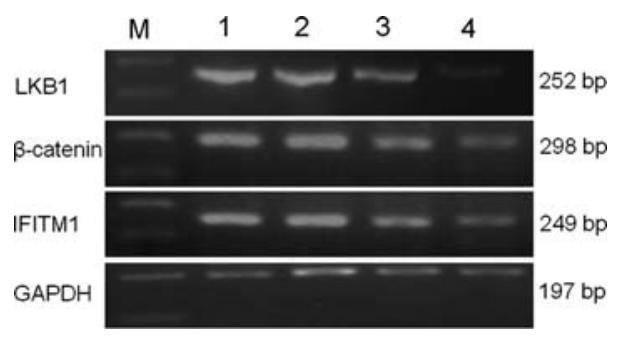

B
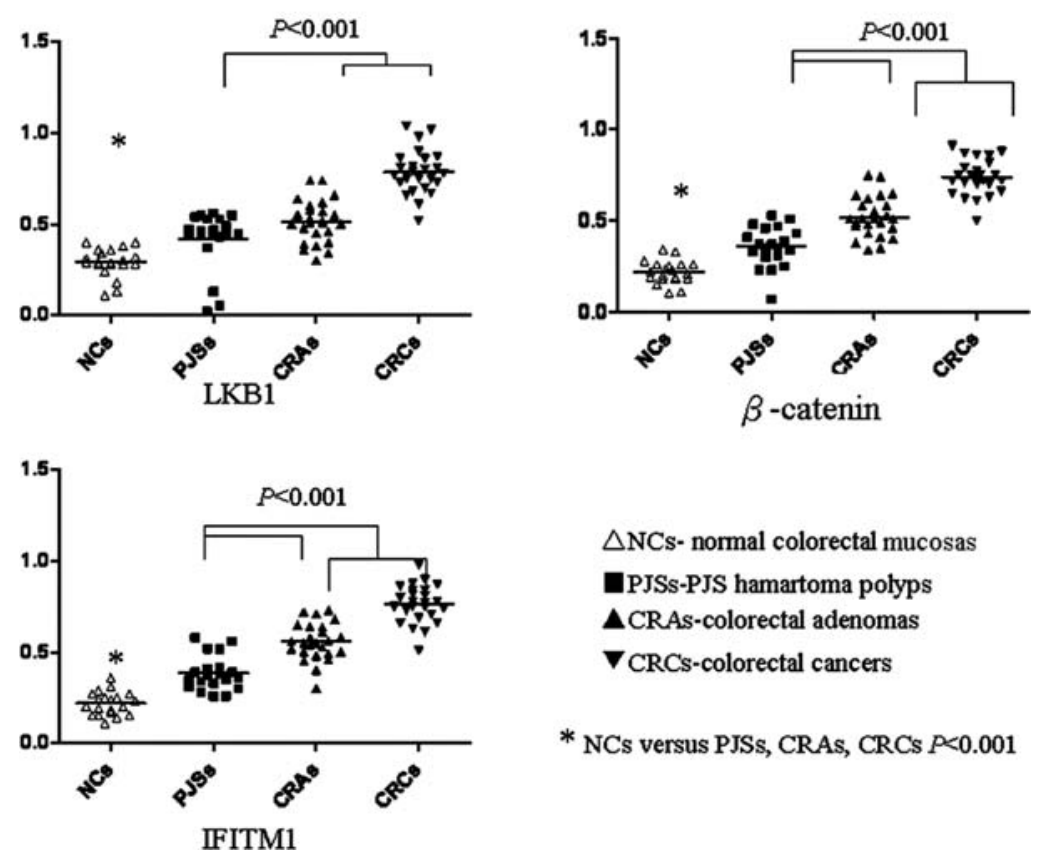

$\triangle \mathrm{NCs}$ - normal colorectal mucosas

DISs-PJS hamartoma polyps

$\triangle$ CRAs-colorectal adenomas

$\boldsymbol{\nabla}$ CRCs-colorectal cancers

* NCs versus PJSs, CRAs, CRCs $P<0.001$

Figure 2. LKB1, ß-catenin and IFITM1 expression was detected in PJSs and other tumors at the mRNA level. (A) Identification of LKB1, ß-catenin and IFITM1 mRNA transcripts using RT-PCR in CRCs (lane 1), CRAs (lane 2), PJS polyps (lane 3) and NCs (lane 4). GADPH expression served as an internal control. (B) The mRNA expression levels of LKB1, B-catenin and IFITM1 in normal colorectal mucosa ( $\mathrm{n}=20$ ), PJS polyps ( $\mathrm{n}=20$ ), colorectal adenoma $(n=25)$ and colorectal adenocarcinoma $(n=25)$.

mean age of the patients bearing PJSs was significantly lower than the mean age of patients bearing CRAs and CRCs $(\mathrm{P}<0.001)$. In regard to the tumor size, there was no significant difference between PJSs and CRAs, whereas the size of the CRCs was significantly larger than that of the PJSs and CRAs $(\mathrm{P}<0.001)$.

LKB1, $\beta$-catenin and IFITM1 expression in PJS hamartoma polyps, CRAs and CRCs at the mRNA level. As shown in Fig. 2A, LKB1 mRNA expression in the NCs was signifiantly lower compared with that in the PJSs, CRAs and CRCs $(\mathrm{P}<0.001)$. There was no significant difference in LKB1 mRNA expression between the PJSs and CRAs ( $\mathrm{P}>0.05)$, but the LKB1 mRNA in the PJSs was significantly lower than that in the CRCs (Fig. 2B, $\mathrm{P}<0.001$ ).

Expression of B-catenin and IFITM1 mRNA in the NCs was significantly lower compared with that in the PJSs, CRAs and CRCs (Fig. 2B, P<0.001). Expression of B-catenin and IFITM1 mRNA in PJSs was significantly lower than that in the CRAs and CRCs (Fig. 2B, $\mathrm{P}<0.001$ ). The IFITM1 mRNA expression pattern was similar to the $B$-catenin mRNA expression profile that showed explicit difference between the PJSs and CRAs (Fig. 2B, P<0.001).
Protein expression of LKB1, $\beta$-catenin and IFITM1 in PJS harmatoma polyps, CRAs and CRCs. Representative profiles of immunostaining for LKB1, $\beta$-catenin and IFITM1 are shown in Fig 3A. NCs were immunostained as the control (Fig 3A-a). LKB1-, B-catenin- and IFITM1-positive cells were mostly evenly scattered throughout the specimens, excluding some adenoma specimens (Fig 3A-d) which showed fractional expression. In the NCs, a faint staining of LKB1 was exhibited in the cytoplasm. Immunoreactivity of LKB1 was found in the cytoplasm of both the PJSs and CRA tumor cells, while moderate or strong cytoplasmic and nuclear expression was observed in most of the CRCs (Fig. 3A, left column).

B-catenin was detected on the cell membranes of most NCs $(95.0 \%)$. The membranous expression of $\beta$-catenin was lower in the PJSs $(6 / 20,30.0 \%)$, CRAs $(11 / 25,44.0 \%)$ and CRCs $(17 / 25,68.0 \%)$. The absence of membranous expression of $\beta$-catenin in PJSs was significantly increased compared with that in the NCs, and decreased compared with that in the CRAs and CRCs $(\mathrm{P}<0.001)$.

In NCs the expression of IFITM1 was observed along the cell membrane. In PJSs, CRA and CRC tumor cells, immunostaining of IFITM1 was detected in the cytoplasm (Fig 3A, right column). These proteins were predominantly 
A

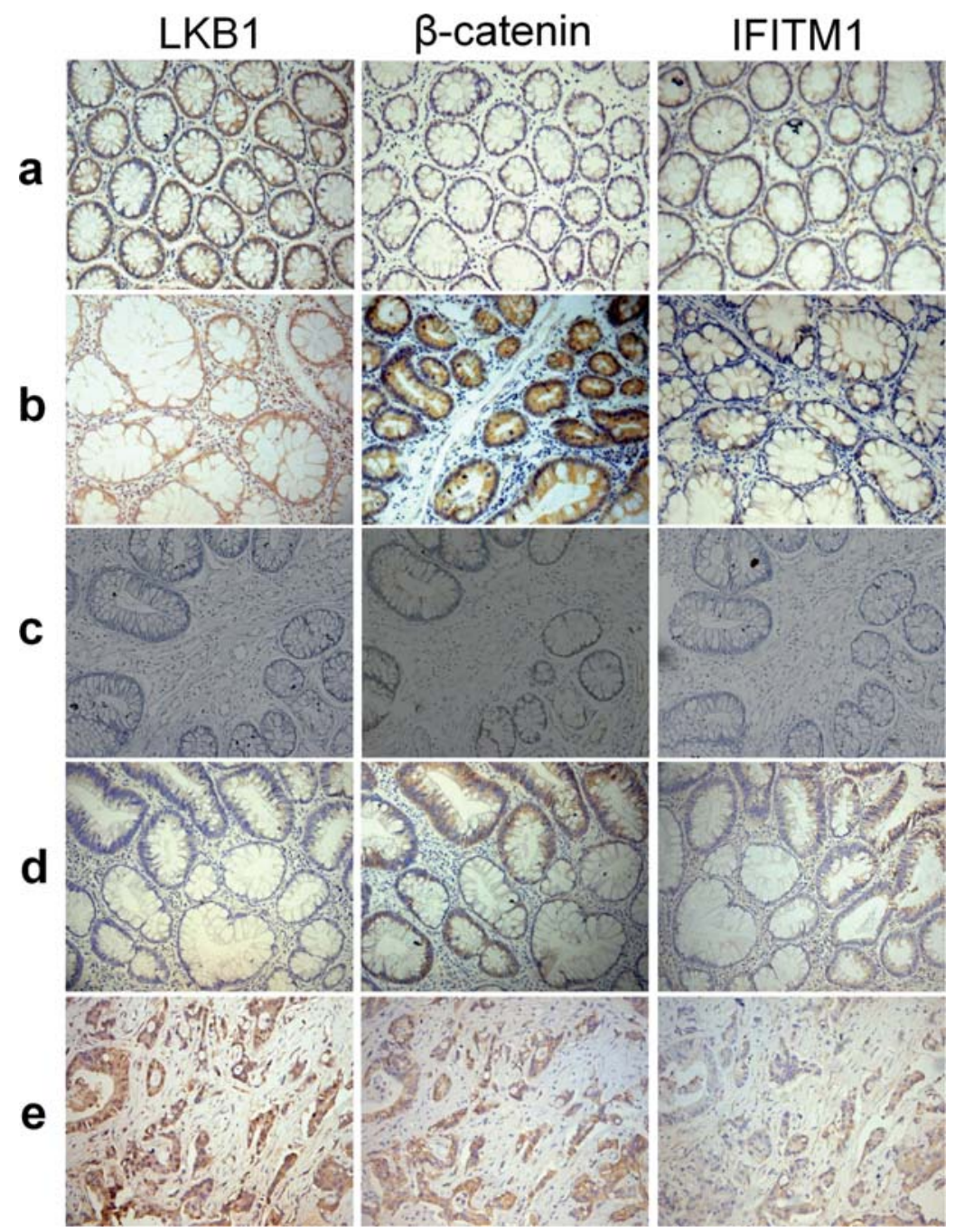

B
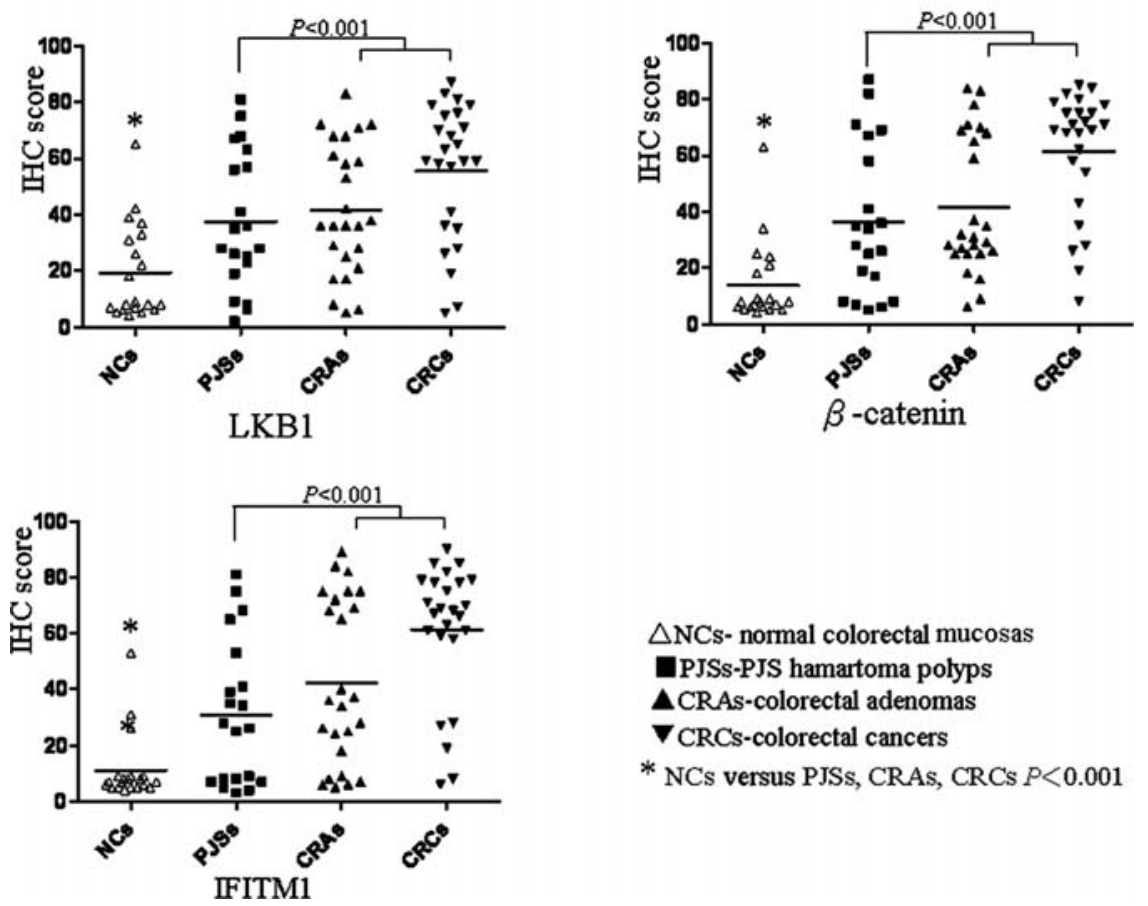

$\triangle$ NCs- normal colorectal mucosas

DISs-PJS hamartoma polyps

$\triangle$ CRAs-colorectal adenomas

$\boldsymbol{\nabla}$ CRCs-colorectal cancers

* NCs versus PJSs, CRAs, CRCs $P<0.001$

Figure 3. (A) Immunohistochemical staining of LKB1, B-catenin and IFITM1 proteins in various colorectal tumors. (a) Normal colorectal mucosas, (b) PJS polyps which were positively stained for LKB1, (c) PJS polyps which were negatively stained for LKB1, (d) colorectal adenomas and (e) colorectal cancers. Magnification, x200. (B) Immunostaining scores of LKB1, B-catenin and IFITM1 in normal intestinal mucosa ( $\mathrm{n}=20$ ), PJS polyps ( $\mathrm{n}=20)$, colorectal adenoma $(n=25)$ and colorectal adenocarcinoma $(n=25)$. Values represent the mean \pm SD. 

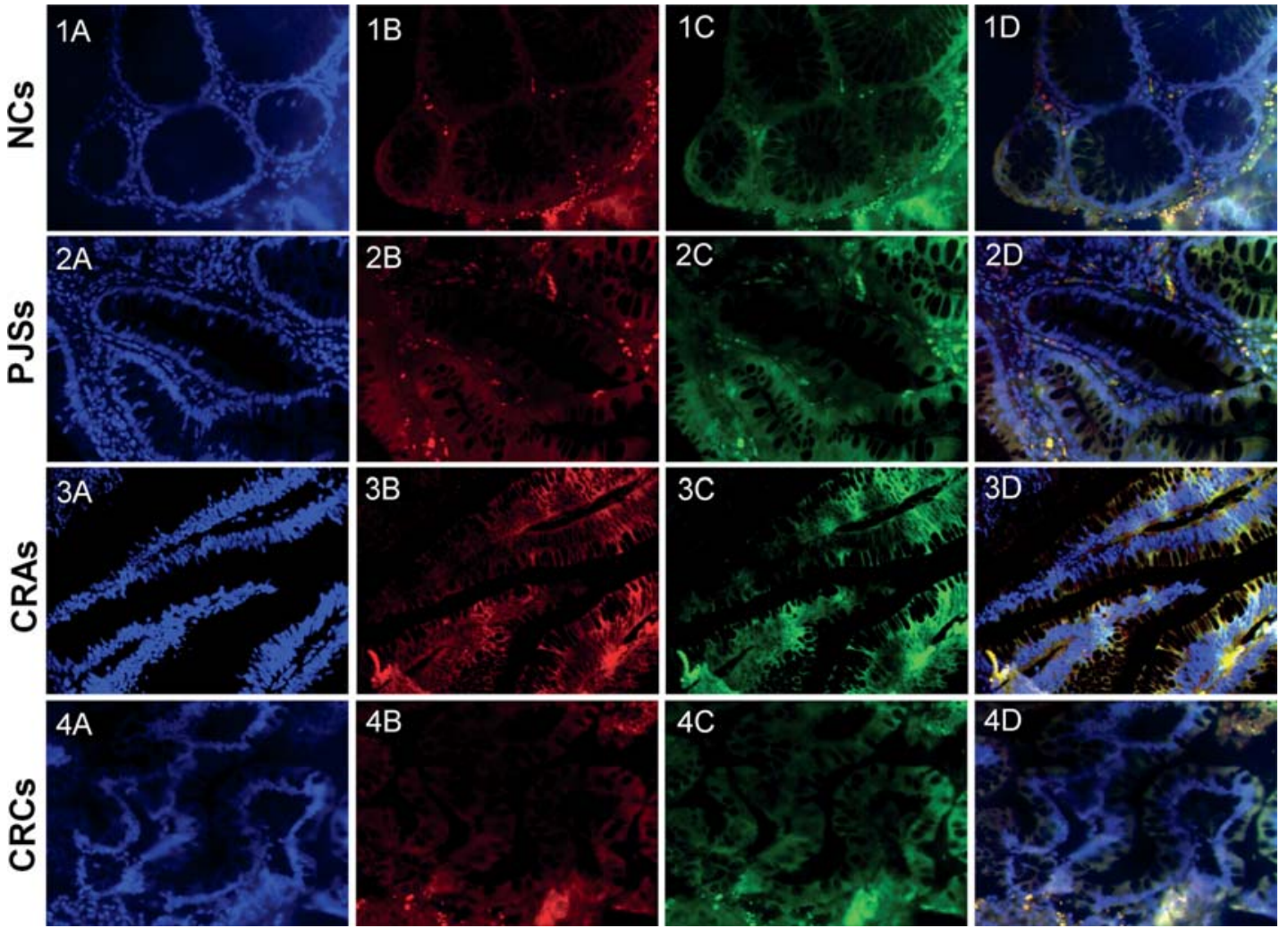

Figure 4. Representative photomicrographs of merged images demonstrate the co-localization of $\beta$-catenin and IFITM1 in sections (2- $\mu \mathrm{m})$ from PJSs and colorectal tumors. B-catenin, red; IFITM1, green. Low levels of IFITM1 (green) and ß-catenin (red) were identified in the sections from normal controls (see Merge). The double-labeled cells evaluated by ß-catenin (red) and IFITM1 (green) co-localization sites (2-PJSs, 3-CRAs, 4-CRCs - A, B, C, D, respectively) were found in the membrane and cytoplasm of sections from PJS polyps and neoplasia of the colorectum (yellow, merge). Images were captured at $\mathrm{x} 400$ magnification $(n \geq 4)$.

Table II. Correlations between the mRNA of the markers.

\begin{tabular}{llccc}
\hline Marker & Correlation & LKB1 & ß-catenin & IFITM1 \\
\hline LKB1 & Correlation coefficient & 1.000 & & \\
& P-value & 0.000 & & \\
ß-catenin & Correlation coefficient & $0.290^{\mathrm{a}}$ & 1.000 & \\
& P-value & 0.039 & 0.000 & \\
IFITM1 & Correlation coefficient & $0.483^{\mathrm{a}}$ & 0.012 & 1.000 \\
& P-value & 0.027 & 0.060 & 0.000 \\
\hline
\end{tabular}

${ }^{\mathrm{a} C}$ Correlation was significant at the 0.05 level (2-tailed).

present in the epithelium in the samples (Fig. 3A, left and middle column).

The immunostaining scores of LKB1, cytoplasmic expression of $\beta$-catenin and IFITM1 in the carcinomas were significantly increased compared with those in the PJSs and CRA tumor cells $(\mathrm{P}<0.001)$. The differences in expression levels for LKB1, $\beta$-catenin and IFITM1 were not significant between the PJSs and CRAs (Fig. 3B).

Notably, four PJS polyps exhibited an absence of LKB1 expression (Fig. 3A-c, left). Only membranous localization of immunostaining for $\beta$-catenin was present in the same
Table III. Correlations between the immunostaining of the markers.

\begin{tabular}{lllll}
\hline Marker & \multicolumn{1}{c}{ Correlation } & LKB1 & B-catenin & IFITM1 \\
\hline LKB1 & Correlation coefficient & 1.000 & & \\
& P-value & 0.000 & & \\
B-catenin & Correlation coefficient & $0.557^{\mathrm{b}}$ & 1.000 & \\
& P-value & 0.000 & 0.000 & \\
IFITM1 & Correlation coefficient & $0.226^{\mathrm{a}}$ & $0.610^{\mathrm{b}}$ & 1.000 \\
& P-value & 0.033 & 0.000 & 0.000 \\
\hline
\end{tabular}

${ }^{\mathrm{a} C}$ Correlation was significant at the 0.05 level (2-tailed). ${ }^{\mathrm{b}}$ Correlation was significant at the 0.01 level (2-tailed).

cases (Fig. 3A-c middle). Very weak/absent immunostaining of IFITM1 was also found in the same PJS polyps (Fig. 3A-c right).

Correlation of LKB1, $\beta$-catenin and IFITM1 expression. Spearman correlations among the expression levels of LKB1, cytoplasmic accumulation of $\beta$-catenin and IFITM1 are shown in Tables II and III. At the mRNA levels, the expression of LKB1 showed significantly positive correlations both with 
$\beta$-catenin $(r=0.290, P=0.039)$ and IFITM1 $(r=0.483$, $\mathrm{P}=0.027)$. In the immunohistochemistry results, the correlation coefficients were LKB1, B-catenin $(\mathrm{r}=0.557, \mathrm{P}=0.000)$; $\beta$-catenin, IFITM1 ( $\mathrm{r}=0.610, \mathrm{P}=0.000)$; LKB 1 , IFITM1 $(\mathrm{r}=0.226, \mathrm{P}=0.033)$, respectively.

Immunofluorescence of colocalization of $\beta$-catenin and IFITM1. Immunofluorescence results demonstrated that the distribution of $ß$-catenin and IFITM1 were similar. In normal tissues they were located mostly in the membranes, and the densities of ß-catenin- and IFITM1-positive cells were low; in PJS tissues and colorectal tumors, there were more B-catenin- and IFITM1-positive cells in the cytoplasm of epithelial cells. The double-labeled-positive cell for B-catenin and IFITM1 commonly existed in the colorectal tumor cells (Fig. 4).

\section{Discussion}

The premalignant potential of PJS hamartomas has not been fully established. LKB1 has a complex cellular role in PJS. Yet, the exact role of LKB1 in PJSs is particularly difficult to understand. Moreover, the role of the Wnt signaling pathway in PJS is controversial.

Immunohistochemical staining of polyps from PJS patients showed that the majority $(16 / 20)$ of hamartomatous polyps exhibited LKB1 staining as previously demonstrated $(28,29)$. Loss of membranous distribution but also cytoplasmic accumulation of $\beta$-catenin staining in the same specimens which were positively stained for LKB1, and high expression for IFITM1 was also revealed in the serial slides. Expression levels of the three markers appeared higher in the PJSs than those in the NCs. These results suggest that Wnt signaling may be activated in a subset of Peutz-Jeghers syndrome polyps. These findings are consistent with previous reports: Back et al (20) and De Leng et al (22) reported that PJS hamartomatous polyps showed nuclear localization of $\beta$-catenin in some epithelial cells; Andreu et al (17) reported that IFITM1 was especially induced in early stages of murine intestinal tumorigenesis. Thus, ß-catenin and IFITM1 may play a regulated role in the progression of PJS harmatomas. Molecular studies may help to define the premalignant potential of PJS hamartomas. Previous studies found that LKB1 expression was increased in cells undergoing continuous or rapid division in PJS (28). Cytoplasmic expression of ß-catenin may be an unfavorable prognostic factor and might represent a higher malignant potential (30-32). In addition, different levels of Wnt signaling activity are likely to account for distinct cellular activities such as proliferation and epithelial-mesenchymal transitions, which prompt tumor growth and malignant behavior (16). IFITM1 was found to be the second most overexpressed gene in highly invasive clones (33), and a high level of IFITM1 expression was found in early and late intestinal neoplasm. Thus, IFITM1 has been identified as a novel candidate gene for tumor invasion $(17,26)$. Here, data demonstrated that their immunostaining scores were associated with the severity of cytoarchitectural atypia. Cytoplasmic staining of LKB1, Bcatenin and IFITM1 tended to be strong and intense in the cytological atypia epithelium of adenomas. Their protein expression was considerably attenuated in the normal epithelial cells. The expression profiles of LKB1, cytoplasmic B-catenin and IFITM1 in PJSs were similar to those in CRAs both at the mRNA and protein levels, which suggest a common biological process in the progression of PJS and adenomatous polyps.

Our data demonstrated that the cytoplasmic ß-catenin level was significantly correlated with LKB1 and IFITM1 expression in the human tumors. Heterogeneous patterns of ß-catenin in PJS polyps may reflect activation of this pathway by other mechanisms, such as the expression of LKB1. The expression of LKB1 may result in an impaired catabolism of ß-catenin, with subsequent cytoplasmic accumulation and loss of membranous B-catenin in PJS hamartomas. These results are consistent with a model in which LKB1 regulated GSK-3ß phosphorylation, then upregulating Wnt signaling and LKB1/XEEK1 is required for $\mathrm{Wnt} / \mathrm{B}$-catenin signaling (13). The regulatory mechanisms behind $\beta$-catenin accumulation in PJSs are still under investigation. Increased expression of LKB1 might be one of the underlying factors for elevated cytoplasmic levels of $\beta$-catenin in PJSs. LKB1 might be involved in the accumulation of cytoplasmic $\beta$-catenin and IFITM1 in PJSs.

Recent studies reported that IFITM1 is the key regulator of $\beta$-catenin signaling in gastrointestinal tumors $(17,18)$. Our result suggested that IFITM1 expression was positively correlated with cytoplasmic ß-catenin level, and immunofluorescence results demonstrated that the distribution of ß-catenin and IFITM1 was similar. Double labeled-positive cells for $\beta$-catenin and IFITM1 commonly existed in the human tumor tissues. ß-catenin was co-localized with IFITM1 in the cytoplasm in PJSs and colorectal tumor cells. Thus, the activated ß-catenin signaling pathway including IFITM1 might play an important role in a subset of PJS polyps.

Just as the immunohistochemical observations support some widespread functional role for LKB1 protein expression, loss of LKB1 may play a certain role in the pathogenesis of PJSs. Heterogeneous patterns of LKB1 expression were found in four PJS polyps, and the cellular distribution of B-catenin and IFITM1 also displayed heterogeneous patterns in these PJS polyps. In the 4 cases which were stained negative for LKB1, only membranous localization of immunostaining for B-catenin was present in the same PJS polyps, and very weak/absent immunostaining of IFITM1 was also found in the same PJS polyps, while in the other LKB1-positive PJS tissues, B-catenin was in an activated state. This suggests disrupted $\mathrm{Wnt} / \mathrm{B}$-catenin signaling in response to loss of LKB1 in epithelial cells of PJSs. The kinase activity and the cyto-plasmic localization of LKB1 are necessary for this protein to perform its function (34). This implies that at least some of the targets of LKB1 are likely to be cytoplasmic.

To date, these conclusions remain speculative since the exact mechanisms of polyp formation in the hereditary polyposis syndromes of the hamartomatous type are not fully understood. Future investigations must focus on the specific interactions between the mutated gene products (LKB1) and the cellular ß-catenin regulatory system in PJSs and other types of human tumors. Recognition of this new mechanism of tumor initiation and progression will allow a new approach to the design of LKB1-regulated molecules. 


\section{Acknowledgements}

The authors thank Professors Yali Zhang and Bo Jiang for administrative help for the experiments. Y.Z. reviewed all of the tissue slices. B.J. participated in the design of the study.

\section{References}

1. Jansen M, de Leng WW, Baas AF, Myoshi H, Mathus-Vliegen L, Taketo MM, Clevers H, Giardiello FM and Offerhaus GJ Mucosal prolapse in the pathogenesis of Peutz-Jeghers polyposis. Gut 55: 1-5, 2006

2. Hemminki A: The molecular basis and clinical aspects of PeutzJeghers syndrome. Cell Mol Life Sci 55: 735-750, 1999.

3. Van der Weyden L, Jonkers J and Bradley A: Cancer: stuck at first base. Nature 419: 127-128, 2002.

4. Hearle N, Schumacher V, Menko FH, et al: Frequency and spectrum of cancers in the Peutz-Jeghers syndrome. Clin Cancer Res 12: 3209-3215, 2006

5. Mehenni H, Resta N, Guanti G, Mota-Vieira L, Lerner A, Peyman M, Chong KA, Aissa L, Ince A, Cosme A, Costanza MC Rossier C, Radhakrishna U, Burt RW and Picard D: Molecular and clinical characteristics in 46 families affected with PeutzJeghers syndrome. Dig Dis Sci 52: 1924-1933, 2007.

6. Boardman LA, Couch FJ, Burgart LJ, Schwartz D, Berry R, McDonnell SK, Schaid DJ, Hartmann LC, Schroeder JJ, Stratakis CA and Thibodeau SN: Genetic heterogeneity in Peutz-Jeghers syndrome. Hum Mutat 16: 23-30, 2000.

7. McGarrity TJ, Kulin HE and Zaino RJ: Peutz-Jeghers syndrome. Am J Gastroenterol 95: 596-604, 2000.

8. McGarrity TJ and Amos C: Peutz-Jeghers syndrome: clinicopathology and molecular alterations. Cell Mol Life Sci 63: 2135-2144, 2006.

9. Marignani PA: LKB1, the multitasking tumour suppressor kinase. J Clin Pathol 58: 15-19, 2005.

10. Carretero J, Medina PP, Blanco R, Smit L, Tang M, Roncador G, Maestre L, Conde E, Lopez-Rios F, Clevers HC and SanchezCespedes M: Dysfunctional AMPK activity, signaling through mTOR and survival in response to energetic stress in LKB1deficient lung cancer. Oncogene 26: 1616-1625, 2007.

11. Shaw RJ, Kosmatka M, Bardeesy N, Hurley RL, Witters LA, DePinho RA and Cantley LC: The tumor suppressor LKB1 kinase directly activates AMP-activated kinase and regulates apoptosis in response to energy stress. Proc Natl Acad Sci USA 101: 3329-3335, 2004

12. Mukherjee P, Mulrooney TJ, Marsh J, Blair D, Chiles TC and Seyfried TN: Differential effects of energy stress on AMPK phosphorylation and apoptosis in experimental brain tumor and normal brain. Mol Cancer 7: 37-52, 2008.

13. Ossipova O, Bardeesy N, DePinho RA and Green JB: LKB1 regulates Wnt signaling in vertebrate development. Nat Cell Biol 5: 889-894, 2003

14. Giles RH, van Es JH and Clevers H: Caught up in a Wnt storm: Wnt signaling in cancer. Biochim Biophys Acta 1653: 1-24, 2003.

15. Clevers H: Wnt breakers in colon cancer. Cancer Cell 5: 5-6, 2004

16. Fodde R and Brabletz T: Wnt/beta-catenin signaling in cancer stemness and malignant behavior. Curr Opin Cell Biol 19: 150-158, 2007.

17. Andreu P, Colnot S, Godard C, Laurent-Puig P, Lamarque D, Kahn A, Perret C and Romagnolo B: Identification of the IFITM family as a new molecular marker in human colorectal tumors. Cancer Res 66: 1949-1955, 2006.

18. Lickert H, Cox B, Wehrle C, Taketo MM, Kemler R and Rossant J: Dissecting Wnt/beta-catenin signaling during gastrulation using RNA interference in mouse embryos. Development 132: 2599-2609, 2005.
19. Yang Y, Lee JH, Kim KY, Song HK, Kim JK, Yoon SR, Cho D, Song KS, Lee YH and Choi I: The interferon-inducible 9-27 gene modulates the susceptibility to natural killer cells and the invasiveness of gastric cancer cells. Cancer Lett 221: 191-200, 2005.

20. Back W, Loff S, Jenne D and Bleyl U: Immunolocalization of beta catenin in intestinal polyps of Peutz-Jeghers and juvenile polyposis syndromes. J Clin Pathol 52: 345-349, 1999.

21. Herter P, Kuhnen C, Müller KM, Wittinghofer A and Müller O: Intracellular distribution of beta-catenin in colorectal adenomas, carcinomas and Peutz-Jeghers polyps. J Cancer Res Clin Oncol 125: 297-304, 1999.

22. De Leng WW, Westerman AM, Weterman MA, De Rooij FW, Dekken Hv H, De Goeij AF, Gruber SB, Wilson JH, Offerhaus GJ, Giardiello FM and Keller JJ: Cyclooxygenase 2 expression and molecular alterations in Peutz-Jeghers hamartomas and carcinomas. Clin Cancer Res 9: 3065-3072, 2003.

23. Giardiello FM, Brensinger JD, Tersmette AC, Goodman SN, Petersen GM, Booker SV, Cruz-Correa M and Offerhaus JA: Very high risk of cancer in familial Peutz-Jeghers syndrome. Gastroenterology 119: 1447-1453, 2000.

24. Giardiello FM, Welsh SB, Hamilton SR, Offerhaus GJ, Gittelsohn AM, Booker SV, Krush AJ, Yardley JH and Luk GD: Increased risk of cancer in the Peutz-Jeghers syndrome. N Engl J Med 316: 1511-1514, 1987.

25. Ghaffar H, Sahin F, Sanchez-Cepedes M, et al: LKB1 protein expression in the evolution of glandular neoplasia of the lung. Clin Cancer Res 9: 2998-3003, 2003.

26. Hatano H, Kudo Y, Ogawa I, Tsunematsu T, Kikuchi A, Abiko Y and Takata T: IFN-induced transmembrane protein 1 promotes invasion at early stage of head and neck cancer progression. Clin Cancer Res 14: 6097-6105, 2008.

27. Maruyama K, Ochiai A, Akimoto S, Nakamura S, Baba S, Moriya Y and Hirohashi S: Cytoplasmic. beta-catenin accumulation as a predictor of hematogenous metastasis in human colorectal cancer. Oncology 59: 302-309, 2000.

28. Rowan A, Churchman M, Jefferey R, Hanby A, Poulsom R and Tomlinson I: In situ analysis of LKB1/STK 11 mRNA expression in human normal tissues and tumours. J Pathol 192: 203-206, 2000

29. Wei C, Amos CI, Rashid A, Sabripour M, Nations L, McGarrity TJ and Frazier ML: Correlation of staging for LKB1 and Cox-2 in hamartomatous polyps and carcinoma from patients with PeutzJeghers syndrome. J Histochem Cytochem 51: 1665-1672, 2003.

30. Yamada Y, Yoshimi N, Hirose Y, Kawabata K, et al: Frequent $B$-catenin gene mutations and accumulations of the protein in the putative preneoplastic lesions lacking macroscopic aberrant crypt foci appearance, in rat colon carcinogenesis. Cancer Res 60: $3323-3327,2000$.

31. Anderson CB, Neufeld KL and White RL: Subcellular distribution of Wnt pathway proteins in normal and neoplastic colon. Proc Natl Acad Sci USA 99: 8683-8688, 2002.

32. Qiao Q, Ramadani M, Gansauge S, Gansauge F, Leder G and Beger HG: Reduced membranous and ectopic cytoplasmic expression of beta-catenin correlate with cyclin D1 overexpression and poor prognosis in pancreatic cancer. Int J Cancer 95: 194-197, 2001

33. Kudo Y, Ogawa I, Kitajima S, Kitagawa M, Kawai H, Gaffney PM, Miyauchi M and Takata T: Periostin promotes invasion and anchorage-independent growth in the metastatic process of head and neck cancer. Cancer Res 66: 6928-6935, 2006.

34. Nezu J, Oku A and Shimane M: Loss of cytoplasmic retention ability of mutant LKB1 found in Peutz-Jeghers syndrome patients. Biochem Biophys Res Commun 261: 750-755, 1999. 